\title{
Effect of plastic mulching on the accumulation and distribution of macro and micro plastics in soils of two farming systems in Northwest China
}

\author{
Fanrong Meng ${ }^{1,2}$, Tinglu Fan ${ }^{3}$, Xiaomei Yang ${ }^{\text {Corresp., }, 1,4}$, Michel Riksen ${ }^{1}$, Minggang Xu ${ }^{\text {Corresp., }}{ }^{2}$, Violette Geissen ${ }^{1}$ \\ ${ }^{1}$ Soil Physics and Land Management, Wageningen University, P.O. Box 47, 6700 AA, Wageningen, The Netherlands, Wageningen, NETHERLANDS, \\ Netherlands \\ 2 National Engineering Laboratory for Improving Quality of Arable Land, Institute of Agricultural Resources and Regional Planning, Chinese Academy of \\ Agricultural Sciences, Beijing, 100081, China, Beijing, China \\ 3 Dryland Agriculture Institute, Gansu Academy of Agricultural Sciences, Lanzhou 730070, Gansu, China, Lanzhou, China \\ 4 College of Natural Resources and Environment, Northwest A\&F University, Yangling, Shaanxi, 712100, PR China, Yangling, China \\ Corresponding Authors: Xiaomei Yang, Minggang Xu \\ Email address: xiaomei.yang@wur.nl, xuminggang@caas.cn
}

Background: Inappropriate disposal of the plastic mulching debris could create macroplastics (MaPs) and microplastics (MiPs) pollution in agricultural soil.

Methods: To study the effects of farming systems on accumulation and distribution of agricultural plastic debris, research was carried out on two farming systems in Northwest China. Farming in Wutong Village (S1) is characterized by small plots and low-intensity machine tillage while farming in Shihezi (S2) is characterized by large plots and high-intensity machine tillage. In September 2017, we selected 6 fields in S1, 3 fields with 6-8 years of continuous plastic mulching (CM) as well as 3 fields with over 30 years of intermittent mulching (IM). In S2, we selected 5 cotton fields with $6,7,8,15$ and 18 years of continuous mulching. In both regions, MaPs and MiPs from soil surface to $30 \mathrm{~cm}$ depth $(0-30 \mathrm{~cm})$ were sampled.

Results: The results showed that in S1, MaPs mass in fields with 6-8 years CM (i.e. $97.4 \mathrm{~kg} \cdot \mathrm{ha}^{-1}$ ) were significantly higher than in fields with 30 years IM (i.e. $53.7 \mathrm{~kg} \cdot \mathrm{ha}^{-1}$ ). MaPs in size category of $10-50 \mathrm{~cm}^{2}$ accounted for over $40 \%$ (46.9\% in fields of CM and $44.5 \%$ in fields of IM) of total collected MaPs number. In S2, MaPs mass ranged from $43.5 \mathrm{~kg} \cdot \mathrm{ha}^{-1}$ to $148 \mathrm{~kg} \cdot \mathrm{ha}^{-1}$. MaPs in size category of $2-10 \mathrm{~cm}^{2}$ account for $41.1 \%$ of total collected MaPs number while $0.25-2 \mathrm{~cm}^{2}$ accounted for $40.6 \%$. MiPs in S1 were mainly detected in fields with over 30 years of intermittent mulching (up to 2200 particles $\mathrm{kg}^{-1}$ soil), whereas in $\mathrm{S} 2$ were detected in all fields (up to 900 particles $\mathrm{kg}^{-1}$ soil). The results indicated farming systems could substantially affect the accumulation and distribution of agricultural plastic debris. Continuous plastic mulching could accumulate higher amount of MaPs than intermittent plastic mulching. High-intensity machine tillage could lead to higher fragmentation of MaPs and more severe MiPs pollution. These results suggest that agricultural plastic regulations are needed. 
1 Effect of plastic mulching on the accumulation and

2 distribution of macro and micro plastics in soils of

3 two farming systems in Northwest China

Fanrong Meng ${ }^{1,2}$, Tinglu Fan ${ }^{3}$, Xiaomei Yang ${ }^{2,4}$, Michel Riksen ${ }^{2}$, Minggang Xu ${ }^{1}$,

$6 \quad$ Violette Geissen ${ }^{2}$

7

$8{ }^{1}$ National Engineering Laboratory for Improving Quality of Arable Land, Institute of

9 Agricultural Resources and Regional Planning, Chinese Academy of Agricultural Sciences,

10 Beijing, 100081, China

112 Soil Physics and Land Management Group, Wageningen University, P.O. Box 47, 6700 AA,

12 Wageningen, The Netherlands

${ }^{3}$ Dryland Agriculture Institute, Gansu Academy of Agricultural Sciences, Lanzhou 730070,

14 Gansu, China

$15{ }^{4}$ College of Natural Resources and Environment, Northwest A\&F University, Yangling,

16 Shaanxi, 712100, PR China

17

18 Corresponding Author:

19 Minggang Xu

20 National Engineering Laboratory for Improving Quality of Arable Land, Institute of Agricultural

21 Resources and Regional Planning, Chinese Academy of Agricultural Sciences, Beijing, 100081,

22 China

23 Email address: xuminggang@caas.cn

24 Xiaomei Yang 
25 Soil Physics and Land Management Group, Wageningen University, P.O. Box 47, 6700 AA,

26 Wageningen, The Netherlands

27 Email address: xiaomei.yang@wutr.nl 


\section{Abstract}

30 Background: Inappropriate disposal of the plastic mulching debris could create macroplastics 31 (MaPs) and microplastics (MiPs) pollution in agricultural soil.

32 Methods: To study the effects of farming systems on accumulation and distribution of agricultural 33 plastic debris, research was carried out on two farming systems in Northwest China. Farming in 34 Wutong Village (S1) is characterized by small plots and low-intensity machine tillage while 35 farming in Shihezi (S2) is characterized by large plots and high-intensity machine tillage. In 36 September 2017, we selected 6 fields in S1, 3 fields with 6-8 years of continuous plastic mulching 37 (CM) as well as 3 fields with over 30 years of intermittent mulching (IM). In S2, we selected 5 38 cotton fields with 6, 7, 8, 15 and 18 years of continuous mulching. In both regions, MaPs and MiPs 39 from soil surface to $30 \mathrm{~cm}$ depth $(0-30 \mathrm{~cm})$ were sampled.

40 Results: The results showed that in S1, MaPs mass in fields with 6-8 years CM (i.e. $97.4 \mathrm{~kg} \cdot \mathrm{ha}^{-1}$ ) 41 were significantly higher than in fields with 30 years IM (i.e. $53.7 \mathrm{~kg} \cdot \mathrm{ha}^{-1}$ ). MaPs in size category 42 of $10-50 \mathrm{~cm}^{2}$ accounted for over $40 \%$ (46.9\% in fields of CM and $44.5 \%$ in fields of IM) of total 43 collected MaPs number. In S2, MaPs mass ranged from $43.5 \mathrm{~kg} \cdot \mathrm{ha}^{-1}$ to $148 \mathrm{~kg} \cdot \mathrm{ha} \mathrm{P}^{-1}$. MaPs in size 44 category of $2-10 \mathrm{~cm}^{2}$ account for $41.1 \%$ of total collected MaPs number while $0.25-2 \mathrm{~cm}^{2}$ accounted for $40.6 \%$. MiPs in S1 were mainly detected in fields with over 30 years of intermittent mulching (up to 2200 particles $\cdot \mathrm{kg}^{-1}$ soil), whereas in S2 were detected in all fields (up to 900 47 particles $\cdot \mathrm{kg}^{-1}$ soil). The results indicated farming systems could substantially affect the accumulation and distribution of agricultural plastic debris. Continuous plastic mulching could accumulate higher mass of MaPs than intermittent plastic mulching. High-intensity machine tillage

51 that agricultural plastic regulations are needed. 
52 Keywords: Plastic film mulching; Microplastics; Low-density polyethylene; Farming systems;

53 Soil pollution. 


\section{Introduction}

55

56

57

58

59

60

61

62

63

64

65

66

67

68

69

70

71

72

73

74 76

75 in the food chain. MiPs could also negatively affect the growth and survival rate of soil organisms

Plastic mulching is a widespread agricultural practice in arid and semi-arid agricultural areas. Plastic mulching has been proved to be beneficial in conserving water (Ingman et al., 2017), increasing surface soil temperature, modifying microclimates (Tarara, 2000), reducing weeds, discouraging pests(Díaz-Hernández and Salmerón, 2012), and improving crop productivity (Scarascia-Mugnozza et al., 2011). Plastic mulching has experienced a rapid growth in China since it was first introduced in the 1980s (Cai et al., 2013; Ma et al., 2018), growing from 6000 tons used on 117,000 hectares of land in 1982 to about 1.5 million tons used on 18.4 million hectares of land in 2016 (NBSC, 2017). Due to the high labour-intensity and costs of removal, plastic films were usually left in fields after crops were harvest. There is a growing concern about the impacts of these discarded plastics on soil health and food security (Blanco et al., 2018; Briassoulis et al., 2013).

Macro-size plastics (MaPs) in agricultural fields have been reported could significantly reduced the gravimetric water mass and bulk density of soils, decreases macro-pores and alters soil water distribution(Jiang et al., 2017). Zhang et al. (2017) indicated that soil enzyme activity and soil fertility could be significantly decreased when plastic debris mass reached up to $450 \mathrm{~kg} \cdot \mathrm{ha}^{-}$ 1. Plastic debris may act as potential pesticide vehicles in soil and lead to unpredictable migration of pesticides in the soil matrix (Ramos et al., 2015; Teuten et al., 2009). Furthermore, agricultural plastic mulching has been reported as a source of microplastics (MiPs) in terrestrial environment (de Souza Machado et al., 2018; Huang et al., 2020; Scheurer and Bigalke, 2018). Rillig (2012) reported that MiPs could be ingested by soil mesofauna and microfauna and thus, bio-accumulate and influence soil function (Cao et al., 2017; Huerta Lwanga et al., 2016). In addition, plastic 
77 debris could be easily migrated into surrounding ecosystems (Rezaei et al., 2019; Vermeiren et al., 78 2016). It has been widely reported that plastic debris poses considerable threats by choking and 79 starving wildlife (Barnes et al., 2009) and by transferring and releasing chemicals into aquatic 80 ecosystems (Teuten et al., 2009). Hence, it is of vital importance to monitor the dynamic of plastic 81 debris.

Previous research that document agricultural plastic debris accumulation mainly attributed 83 it to the mulching time. Ma and Yang (2013) reported that plastic debris accumulated in Xinjiang 84 fields at a rate of 27.6, 30.8 and $42.3 \mathrm{~kg} \cdot \mathrm{ha}^{-1}$ with $<10,10-20$ and 20-30 years of mulching, 85 respectively. He et al. (2018) observed that the annual rate of plastic debris accumulation was $15.69 \mathrm{~kg} \cdot \mathrm{ha}^{-1}$ in Xinjiang. However, other factors such as the size of plastic debris, continuous or 87 intermittent mulching and debris recycling activities could also affect the accumulation of MaPs 88 in agricultural soils (Briassoulis et al., 2004; Ma and Yang, 2015; Qi et al., 2020; Steinmetz et al., 89 2016). In different farming regions, different farming practices (mechanical tillage intensity, 90 plastic mulching techniques and etc.) were applied due to the local soil type and climate, thus 91 resulting in different accumulation patterns of plastic debris. Yan et al. (2008) conducted a field 92 observation in Xinjiang (Northwest China) and found that highest amount of MaPs reached up to $93308 \mathrm{~kg} \cdot \mathrm{ha}^{-1}$, MaPs were mainly concentrated in $0-10 \mathrm{~cm}$ soil. They also found that $80 \%$ of MaPs 94 detected in their study were in the size category of $1-25 \mathrm{~cm}^{2}$. Li et al. (2017) conducted a field 95 observation in Qingdao (Middle China) and found the amount of MaPs in agricultural fields was 96 ranging between $11-69 \mathrm{~kg} \cdot \mathrm{ha}^{-1}$. MaPs were mainly concentrated in 0-20 $\mathrm{cm}$ soil. However, in their 97 study, the detected MaPs were mainly in the size category of $>100 \mathrm{~cm}^{2}$. Therefore, farming system 98 plays an important role in agricultural plastic pollution. Unfortunately, the effects of different 99 farming systems on plastic accumulation remained inadequate addressed. 
In this current work, we assumed that different farming systems could affect the

101 accumulation and distribution of plastic debris in agricultural soil. We hypothesized that 1). Under

102 the same farming system, continuous plastic mulching could accumulate more MaPs mass than

103 intermittent plastic mulch; (2) farming system of higher mechanical intensity could lead to higher

104 fragmentation of MaPs and create more MiPs than farming system of lower mechanical intensity.

105 To test our hypothesis, we selected two regions in Northwest China that both have a long history 106 (dating back to the mid-1980s) of plastic mulching application but with different farming systems

107 (Fig.1). First study region is characterized by small-scale farmlands with low levels of agricultural

108 mechanization. Second study region is characterized by large-scale farmlands and high levels of 109 agricultural mechanization. We examined the accumulation and distribution of MaPs and MiPs in

110 0-30 cm soil of two study regions. In our paper, MaPs were defined as plastic particles with a size 111 area of $>0.25 \mathrm{~cm}^{2}$ (which was the smallest MaPs size we collected from field, Supplementary file

112 1, Fig.S3a). MiPs were defined as plastic particles derived from LDPE plastic mulching film with 113 a diameter of $<2 \mathrm{~mm}$ and a density smaller than $1 \mathrm{~g} \cdot \mathrm{cm}^{-3}$ due to plastic mulching was considered 114 as the main source for plastic pollution in the selected two study regions. We hope to provide a 115 basis information for future efforts aimed at controlling and managing plastic pollution in 116 agricultural soils.

\section{Materials \& Methods}

\section{Study area description}

The first study region located in Wutong Village $\left(\boldsymbol{S} 1,35^{\circ} 29^{\prime} \mathrm{N}, 1^{\circ} 7^{\circ} 29^{\prime} \mathrm{E}\right)$, Gansu

120 Province, where the cultivated area is 2779 ha. S1 is characterized by small-scale farmlands 121 (usually smaller than 1 ha according to farmers) and low levels of agricultural mechanization.

122 Tillage is performed using small rotary cultivators at a depth of $30 \mathrm{~cm}$ and harvesting is mainly 
123 done manually. In S1, farmers predominantly practiced full film flat mulching (FF, Fig. 2A). The

124 plastic film was transparent and made from low-density polyethylene (LDPE) (Table S1) and there

125 was an annual usage of $150 \mathrm{~kg} \cdot \mathrm{ha}^{-1}$ in this area. Plastic mulching had been intermittently applied

126 to the fields over a span of 30 years at 3- or 4-year intervals. Maize (Zea mays L.) was the main

127 crop for which plastic mulching was used. After the maize had been sown, the land was covered

128 with the plastic much. The maize plants grew through the plastic mulch. After harvesting the

129 maize, the plastic films were manually removed from the soil before preparing the land for the

130 next crop. The common practice in study area S1 was to rotate maize with soybean (Glycine max),

131 oilseed rape (Brassica napus) and winter wheat (Triticum aestivum L.). For these other crops,

132 plastic mulching was not used. The common cultivation pattern was three harvests every two years.

133 However, in recent years, some farmers have switched to a monoculture of maize due to its

134 increasing economic value. In S1, we selected 6 fields to investigate the impacts of monoculture

135 and crop rotation on agricultural plastic debris accumulation and distribution (Fig.1A). Fields S1-

1361 (contact: Shangzhong Li), S1-2 (contact: Yi Dang) and S1-3 (contact: Lei Wang) were

137 monocultured with maize, with 6,8 and 6 years of continuous mulching, respectively. In fields

138 S1-4, S1-5 and S1-6, crops were rotated. In S1-4 (contact: Limin Wang), the crop rotation was

139 oilseed rape (Early September 2015 to mid-June 2016), Winter Wheat (late September/early

140 October 2017 to the end of May 2018), and Soybean (mid-June 2017 to late September 2017). In

141 S1-5 (contact: Sanzhi LI), the crop rotation was Maize (mid-April 2016 to mid-September 2016)

142 and Winter Wheat (late September/early October 2017 to the end of May 2018). In S1-6 (contact:

143 Limin Wang), the crop rotation was Maize (mid-April 2016 to mid-September 2016), left Fallow

144 (mid-September 2016 to mid-June 2017), and Soybean (mid-June 2017 to late September 2017). 
146 the cultivated area is 971301 ha. S2 is characterized by large-scale farmlands (larger than 3 ha per

147 field) and high levels of agricultural mechanization. Tillage is performed using large rotary

148 cultivators at a depth of $30 \mathrm{~cm}$ and harvesting is done using a cotton picker. In S2, the mulching

149 pattern was flat cover combined with drip irrigation (FCDI, Fig.2B). The use of plastic mulching

150 coupled with irrigation was initiated in the 1990s. The annual usage of plastic film in S2 was 60

$151 \mathrm{~kg} \cdot \mathrm{ha}^{-1}$. The plastic film was transparent and made from LDPE \& LLDPE (linear low-density

152 polyethylene) (Table S1). We selected 5 fields with 6 (contact: Yu Liu), 7 (contact: Yu Liu), 8

153 (contact: Gongmao Wang), 15 (contact: Jihong Shi), and 18 (contact: Jiancheng Liu) years of

154 continuous FCDI mulching (Fig.1B). All the fields were planted with the same type of cotton

155 cultivar and the same fertilization practices were followed. After harvesting, the plastic films were

156 machinery removed from the fields along with the cotton stalks.

157 The farming system chosen in each region was representative of the typical situation for 158 the local farmers. Both regions have a temperate continental climate. The climate data from 2017 159 of two study region and the soil information are shown in Table S1. The climate data was recorded 160 by a local weather station. For this research, we assumed that the mixing procedure mainly 161 depended on the different farming systems prevalent in the two study regions. Hence, only farming 162 systems and crops from these regions were taken into account in current work.

Field sampling of macroplastics and soil samples

MaPs were manually collected using a quadrat sampling method. In each selected field, on 165 the diagonal line (Fig.2C), we randomly dug 3 quadrats (each quadrat was $100 \mathrm{~cm}$ long, $50 \mathrm{~cm}$ wide and $30 \mathrm{~cm}$ deep and covered two crop rows, Fig. 2D). Each sampling quadrat was then separated into three depth layers: $0-10 \mathrm{~cm}, 10-20 \mathrm{~cm}$ and $20-30 \mathrm{~cm}$. The entire soil mass from each 
168 layer were then put onto a "flat polypropylene (PP) wire weaved mesh sheet" (Supplementary file

169 1, Fig.S1). To prevent further fragmentation of the MaPs during the collection process, visible

170 MaPs were gently picked out by hand from the entire mass of each layer of the sampled quadrat.

171 Each layer of the sampling quadrat was carefully checked three times. The collected MaPs from

172 each layer were then stored in a PP bag. All the collected MaPs samples then transferred to the

173 laboratory for further analysis. Totally, resulted in 54 MaPs samples in S1 (6 fields $\times 3$ quadrats $\times$

1743 layers) and 45 MaPs samples in S2 (5 fields $\times 3$ quadrats $\times 3$ layers).

175 Macroplastic quantification and residual ratio

176 In the laboratory, all MaPs were cleaned thoroughly. First, plant roots, soil, sand, etc. were 177 separated manually from the MaPs. Next, MaPs were unfolded and washed with tap water three 178 times in a PP basin (solid colour) until the films were transparent. Then, the cleaned MaPs from 179 each layer of soil quadrat were stored in a $500 \mathrm{~mL}$ glass beaker that was filled with $300 \mathrm{~mL}$ of tap 180 water. The beaker was put into a ultrasonic cleaner (KQ 3200DA, KUNSHAN ULTRASONIC 181 INSTRUMENTS CO., LTD) for $1 \mathrm{~h}$ to remove any fine sands attached to the MaPs. The MaPs 182 then were stored in a PP mesh bag $(12 * 15 \mathrm{~cm}$, diameter $1 \mathrm{~mm})$ and air-dried for 2-days. The 183 collected MaPs were present in arbitrary shapes, i.e. curved together and flake shape 184 (Supplementary file 1, Fig.S2). All the collected MaPs were gently spread and measured by using 185 graph paper. The smallest size of collected MaPs was measured $0.25 \mathrm{~cm}^{2}$ (Supplementary file 1, 186 Fig.S3a). We separate the plastic debris into five size groups: $0.25-2 \mathrm{~cm}^{2}, 2-10 \mathrm{~cm}^{2}, 10-50 \mathrm{~cm}^{2}$, $18750-100 \mathrm{~cm}^{2}$, and $>100 \mathrm{~cm}^{2}$ (Supplementary file 1, Fig.S3b-f). For each size group, MaPs were 188 weighed using an analytical balance (METTLER AE 200, METTLER AE 200, MARSHALL SCIENCE, accuracy of $0.1 \mathrm{mg}$ ) and the number of particles (p) was counted. The concentrations 
190 of MaPs were recorded as mass $\left(\mathrm{kg} \cdot \mathrm{ha}^{-1}\right)$ and number $\left(\mathrm{p} \cdot \mathrm{ha}^{-1}\right)$. The mass and number were 191 calculated as follows:

192

193

194

195

196

197

198

199

200

201

202

203

204

205

206

207

208

209

210

211

212

213

$$
\begin{aligned}
\left(\mathbf{M}_{i} / \mathbf{S}\right) * 100 & =\text { Mass }\left(\mathrm{kg} \cdot \mathrm{ha}^{-1}\right) \\
\left(\mathbf{N}_{i} / \mathbf{S}\right) * \mathbf{1 0 0} & =\text { Number }\left(\mathrm{p} \cdot \mathrm{ha}^{-1}\right)
\end{aligned}
$$

Where, $\mathbf{M}_{i}(\mathrm{mg})$ is the total weight of collected MaPs from each of the $10 \mathrm{~cm}$ sampling depths. $\mathbf{S}\left(\mathrm{cm}^{2}\right)$ is the surface area of each sampling quadrat. The conversion coefficient from $\mathrm{mg} \cdot \mathrm{cm}^{-2}$ to $\mathrm{kg} \cdot \mathrm{ha}^{-1}$ is $\mathbf{1 0 0} . \mathbf{N}_{i}(\mathrm{p})$ is the total number of collected MaPs from each of the $10 \mathrm{~cm}$ sampling depths.

The residual ratio of MaPs per selected field, which referred to as the amount of MaPs found in soil in relation to the total applied biofilm amount, was calculated with the following equation:

$$
\mathbf{U} * \mathbf{t}=\text { Total input }
$$

Mass / Total input $* 100=$ Residual ratio $(\%)$

where, $\mathbf{U}$ is the annual plastic film usage, $\mathrm{S} 1$ is $150 \mathrm{~kg} \cdot \mathrm{ha}^{-1}$, and $\mathrm{S} 2$ is $60 \mathrm{~kg} \cdot \mathrm{ha}^{-1}$. $\mathbf{t}$ is the number of years of plastic mulching application. Mass is the total weight of MaPs collected from the selected fields. For fields where mulching was used continuously, $\mathbf{t}$ is equal to the mulching year. However, for the intermittent use of plastic mulching in the S1 region, $\mathbf{t}$ is assumed to be 7 years, which was calculated using the plastic mulching interval of every 4 years during the 30 years of mulching history.

\section{Microplastic extraction and identification}

Soil samples for MiPs extraction were collected from the sides of the pits that were dug out of the soil quadrats (Fig. 2C). For each $10 \mathrm{~cm}$ depth, $1 \mathrm{~kg}$ of soil sample from three randomly selected sampling points were directly collected in situ and homogenized. The soil samples were extracted using a metal augur and transferred to the laboratory in PP plastic bags (Supplementary 
214 file 1, Fig.S4). Once in the lab, the soil samples were air dried in open paper trays in a room without 215 visible plastic materials. The soil was then sieved through a $2 \mathrm{~mm}$ steel sieve for the further MiPs 216 extraction. A control field had never been applied with plastic mulching was selected in each study 217 region (Contact of control field in S1: Jianjun Zhang; in S2: Yu Liu). A soil sample from each 218 control field was collected to check whether the PP plastic containers polluted the soil samples 219 with plastic.

220 MiPs extraction was carried out following a float method published by Zhang et al. (2018).

221 222 223 224 225 226 227 228 229

This method was specially developed for the extraction of LDPE-MiPs. According to Zhang et al. (2018), the recovery rates were $>90 \%$ and the lower limit of detection for this method is $20 \mu \mathrm{m}$. Before the extraction procedure, the MaPs in the soil samples were collected until no more plastic could be seen with the naked eye. Then, $10 \mathrm{~g}$ of the air-dried soil samples were added to $100 \mathrm{ml}$ centrifuge tubes (PP). $50 \mathrm{~mL}$ of distilled water was added to each tube and a glass stick was used to stir the soil and water together in order to get a homogeneous suspension. The glass stirrer was rinsed off using distilled water and the water was then collected in the same centrifuge tube. Next, soil samples were spun 4 times using high speed centrifugation (GL-21MC/GL21MC, CENCE XIANGYI, CHINA) at $14400 \mathrm{~g}$ for $10 \mathrm{~min}$ to separate the soil particles from the floating materials. The resulting supernatant was filtered using filter paper (pore diameter $<3 \mu \mathrm{m}$ ). After that, $50 \mathrm{~mL}$ of distilled water was added again to each centrifuge tube and then placed in an ultrasonic cleaner (KQ 3200DA, KUNSHAN ULTRASONIC INSTRUMENTS CO., LTD) for $2 \mathrm{~h}$ in order to isolate any MiPs that might have still been adsorbed on soil micro aggregates. The samples were then centrifuged for a $5^{\text {th }}$ time. Finally, the filter papers (pore diameter $<3 \mu \mathrm{m}$ ) with the extracted MiPs were dried in an oven (TYPE A $1500-145$, KEMA KEUR) at $60^{\circ} \mathrm{C}$ to a constant weight and stored 
236 in glass Petri dishes for optical inspection. The soil samples from the control fields were also put 237 through the same procedure for extracting MiPs.

238 As a quality control measure, each set of soil samples (n) from each study site ( $\mathrm{n}=18$ in $\mathrm{S} 1$, $239 \mathrm{n}=15$ in S2) contained three blank samples of distilled water. This measurement was used to 240 account for any contamination which could have occurred inside the lab (Mahon et al., 2017;

241 Scheurer and Bigalke, 2018). White cotton lab coats were worn during analysis and sample 242 manipulations.

243 The extracted MiPs were inspected using a microscope (Leica wild M3C, Type S, simple 244 light) at $6.4 \mathrm{X}$ Zoom. The MiPs collected from each filter were placed on glass slides. The glass 245 slides were then inspected using a microscope and a picture " $I$ " was taken. In order to get rid of 246 any organic material from the soil samples that might have interfered with the counting, the glass 247 slides were placed gently on top of an electric heating plate. (TYPE A 1500-145, KEMA KEUR) 248 and heated for $5-7 \mathrm{~s}$ at $130{ }^{\circ} \mathrm{C}$ in order to melt the MiPs. The MiPs were transformed into transparent 249 shiny surfaces which could be easily distinguished from soil particles. The glass slides were then 250 inspected again using the microscope and a second picture " $\boldsymbol{I I}$ " was taken. By comparing pictures 251 " $\boldsymbol{I}$ " and " $\boldsymbol{I}$ ", the melted MiPs could be identified. The smallest microplastic particle detected in 252 our work was $0.49 \mathrm{~mm}$ (44 pixels), calculated by image $\mathrm{J}, 1$ pixel $=0.585 / 60 \mathrm{~mm}$ (microscope at 2536.4 X Zoom). The picture of the setup for identification MiPs is presented in supplementary file 1, 254 Fig.S5.

\section{Limitation of microplastic extraction method}

Only MiPs from LDPE or MiPs with density $<1 \mathrm{~g} \cdot \mathrm{cm}^{-3}$ were able to be extracted due to the 257 water reagent. MiPs with densities higher than $1 \mathrm{~g} \cdot \mathrm{cm}^{-3}\left(\mathrm{e} . \mathrm{g}\right.$. PVC $\left.1.45 \mathrm{~g} \cdot \mathrm{cm}^{-3}\right)$ were not able to be 
258 extracted (Nuelle et al., 2014). However, this method provides a validated method for estimating

259 the presence of LDPE-MiPs in the soil.

260 Data analysis

261 The arcsine square root transformation was applied to the mass and number of MaPs pieces

262 to avoid violating the underlying assumptions of normality. One-way analyses of variances

263 (ANOVAs) were applied to compare the mass and number of MaPs pieces between different fields

264 within the same selected region and different soil layers within the same field, followed by the

265 application of an LSD post hoc test at the $\mathrm{p}<0.05$ level. MaPs mass $\left(\mathrm{kg} \cdot \mathrm{ha}^{-1}\right)$ and number $\left(\mathrm{p} \cdot \mathrm{ha}^{-1}\right)$

266 were presented as "means \pm standard deviations". MiPs that were detected in the fields were

267 presented in raw data in the unit of $\mathrm{p} \cdot \mathrm{kg}^{-1}$ soil due to the highly random distribution of the particles

268 and no statistical test was performed.

269 Results

270

271

272

273

274

275

276

277

278

279

280

\section{Accumulation and distribution of macroplastics in selected agricultural fields}

In $\mathrm{S} 1$, across the 6 selected fields, MaPs number varied from $56.7 \times 10^{4} \mathrm{p} \cdot \mathrm{ha}^{-1}$ to $264.7 \times 10^{4}$ $\mathrm{p} \cdot \mathrm{ha}^{-1}$ and MaPs mass varied from $53.7 \mathrm{~kg} \cdot \mathrm{ha}^{-1}$ to $108 \mathrm{~kg} \cdot \mathrm{ha}^{-1}$ (Table 1 ). Fields with 6 to 8 years of continuous plastic mulching use (S1-1, S1-2 and S1-3) showed significant higher MaPs number (one-way ANOVA, $\mathrm{F}_{5,12}=20.9, \mathrm{p}<0.01$ ) and MaPs mass (one-way ANOVA, $\mathrm{F}_{5,12}=4.24, \mathrm{p}=0.02$ ) than fields with more than 30 years of intermittent plastic mulching use (S1-4, S1-5), except S16, where fields showed similar numbers of MaPs as compared to S1-2. The residual ratios varied from $5.11 \%$ to $12.0 \%$ across the selected fields (Table 2 ). Fields where continuous mulching was practiced (S1-1, S1-2 and S1-3) showed significantly higher residual ratios as compared to fields with intermittent mulching (S1-4, S1-5 and S1-6) (Table 2, one-way ANOVA, $\mathrm{F}_{5,12}=6.89, \mathrm{p}=0.03$ ). The distribution pattern of MaPs in each $10 \mathrm{~cm}$ of $0-30 \mathrm{~cm}$ soil layer across the 6 fields in $\mathrm{S} 1$ are 
281 presented in Table 3. The results showed that MaPs were mainly concentrated in the first $0-10 \mathrm{~cm}$ 282 soil layer, followed by $10-20 \mathrm{~cm}$, and then $20-30 \mathrm{~cm}$. The number of MaPs in the $0-10 \mathrm{~cm}$ layer 283 was significantly higher (one-way ANOVA, $\mathrm{p}<0.01$, Table S6) than the $10-20 \mathrm{~cm}$ and/or $20-30$ $284 \mathrm{~cm}$ soil layers. However, for the mass of MaPs, there were significant differences (one-way 285 ANOVA, more detail showed in Table S6) found between soil layers $0-10 \mathrm{~cm}$ and $10-20 \mathrm{~cm}$ and 286 between soil layers 10-20 cm and 20-30 cm, except for S1-1 and S1-6. In addition, we also 287 compared the number and mass percentage of MaPs in different size categories (Fig.3 and Table 288 S4). Continuous (S1-1, S1-2 and S1-3) and intermittent (S1-4, S1-5 and S1-6) mulching fields 289 showed similar composition patterns. For MaPs number, size category of $10-50 \mathrm{~cm}^{2}$ accounted for 290 highest of the total collected MaPs number (46.9\% for continuous mulching fields and $44.5 \%$ for 291 intermittent mulching fields). Size category of $0.25-2 \mathrm{~cm}^{2}$ accounted for lowest of the total 292 collected MaPs number $(3.55 \%$ for continuous mulching fields and $4.20 \%$ for intermittent 293 mulching fields) (Fig.3A, Fig.3B). Significant differences were observed between different size 294 groups (one-way ANOVA, $\mathrm{F}_{4,40}=148, \mathrm{p}<0.01$ for continuous mulching fields; $\mathrm{F}_{4,40}=35.9, \mathrm{p}<0.01$ 295 for intermittent mulching fields). As for MaPs mass, MaPs in size categories $>100 \mathrm{~cm}^{2}$ and 10-50 296 $\mathrm{cm}^{2}$ contributed highest $(34.8 \%$ and $35.8 \%$ in continuous mulching fields; $42.9 \%$ and $34.2 \%$ in 297 intermittent mulching fields) to the total mass while size category of $0.25-2 \mathrm{~cm}^{2}$ contributed lowest ( $0.16 \%$ for continuous mulching fields and $0.26 \%$ for intermittent mulching fields) (Fig.3D, 299 Fig.3E). Significant differences were observed between different MaPs size groups (one-way 300 ANOVA, $\mathrm{F}_{4,40}=217, \mathrm{p}<0.01$ for continuous mulching fields; $\mathrm{F}_{4,40}=28.4, \mathrm{p}<0.01$ for intermittent 301 mulching fields). In S2, across the selected fields, MaPs number varied from $461 \times 10^{4} \mathrm{p} \cdot \mathrm{ha}^{-1}$ to $2016 \times 10^{4}$ $303 \mathrm{p} \cdot \mathrm{ha}^{-1}$ and MaPs mass varied from $43.5 \mathrm{~kg} \cdot \mathrm{ha}^{-1}$ to $148 \mathrm{~kg} \cdot \mathrm{ha}^{-1}$ (Table 1 . Fields exposed to 15 years 
304 of plastic mulching use (S2-4) showed significant higher MaPs number (one-way ANOVA, $305 \mathrm{~F}_{4,10}=61.7 \mathrm{p}<0.01$ ) and mass (one-way ANOVA, $\mathrm{F}_{4,10}=17.1 \mathrm{p}<0.01$ ) than other selected fields. The 306 residual ratios varied from $7.51 \%$ to $21.2 \%$ (Table 2 ). The field exposed to 18 years of plastic 307 mulching use (S2-5) showed the lowest residual ratio, which was only significantly lower than 308 field S1-2 (Table 2, one-way ANOVA, $\mathrm{F}_{4,10}=2.68, \mathrm{p}=0.09$ ). The distribution pattern of MaPs in 309 each $10 \mathrm{~cm}$ soil 0-30 cm across the 5 fields in S2 are presented in Table 4. MaPs were mainly 310 concentrated in the first $0-10 \mathrm{~cm}$ soil layer, followed by $10-20 \mathrm{~cm}$ and $20-30 \mathrm{~cm}$. For the numbers 311 of MaPs, the significant differences were mainly found between the $0-10 \mathrm{~cm}$ and $20-30 \mathrm{~cm}$ soil 312 layers (one-way ANOVA, one-way ANOVA, more detail showed in Table S7). For the mass of 313 MaPs, the significant differences (one-way ANOVA, more detail showed in Table S7) were found 314 between soil layers $0-10 \mathrm{~cm}$ and $10-20 \mathrm{~cm}$ and between soil layers $10-20 \mathrm{~cm}$ and $20-30 \mathrm{~cm}$, except 315 for S2-1 and S2-5. In S2, we also compared the number and mass percentage of MaPs in different 316 size categories (Fig.3, Table S4). For MaPs number (Fig. 3C), the highest contributors were size 317 categories of $0.25-2 \mathrm{~cm}^{2}(40.6 \%)$ and $2-10 \mathrm{~cm}^{2}(41.1 \%)$. The lowest contributor was size category 318 of $>100 \mathrm{~cm}^{2}(1.09 \%)$. Significant differences were observed between different groups (one-way 319 ANOVA, $\mathrm{F}_{4,70}=18.4, \mathrm{p}<0.01$ ). For MaPs mass (Fig.3F), the highest contributor was size category 320 of $10-50 \mathrm{~cm}^{2}(36.4 \%)$, the lowest contributor was size category of $0.25-2 \mathrm{~cm}^{2}(26.2 \%)$. The 321 significant differences between each group were observed (one-way ANOVA, $\mathrm{F}_{4,70}=172, \mathrm{p}<0.01$ ).

322

323

324 325

\section{Occurrence of microplastics in agricultural soils}

In two study regions, the occurrence of MiPs was highly random and only the raw data were presented in the form of $\mathrm{p} \cdot \mathrm{kg}^{-1}$. No MiPs were detected in the control sites and quality controls.

Peer] reviewing PDF | (2020:07:50600:1:2:NEW 3 Oct 2020) 

mulching fields, MiPs were only detected in S1-1, no MiPs were detected in S1-2 or S1-3. The highest MiPs concentration of $2200 \mathrm{p} \cdot \mathrm{kg}^{-1}$ was detected in the $20-30 \mathrm{~cm}$ layer of S1-5, which with 30 years intermittent mulching history. In S2, MiPs were detected in all the selected fields while not all the soil layers (Table 6). In S2-5, MiPs were detected in all the soil samples. The highest MiPs concentration $\left(900 \mathrm{p} \cdot \mathrm{kg}^{-1}\right)$ was detected in the $0-10 \mathrm{~cm}$ soil layer of S2-3 (8 years mulching) and S2-5 (18 years mulching).

333

334 335 336 337 338

\section{Discussion}

In current research, we aimed to examine the characteristics of the MaPs and MiPs accumulation and distribution under two farming systems. Many previous research attributed the accumulation solely to the mulching year (He et al., 2018; Ma and Yang, 2015). Understanding the impacts from other factors of different farming system is essential for regulating agricultural plastic film management. However, relevant knowledge is still limited.

\section{Accumulation and distribution of macroplastics in agricultural soils}

In S1, fields with 6-8 years of continuous mulching (S1-1, S1-2 and S1-3) contained significant higher MaPs numbers and mass than fields with 30 years of intermittent mulching (S14, S1-5 and S1-6). One possible explanation might be attributed to the removal activity by farmers. In $\mathrm{S} 1$, according to local farmers, $80 \%$ of applied plastic films (remained intact and could be easily collected) were manually removed after the harvesting of mulched crop and before sowing of the next rotated crop. In addition, the remained smaller particles (could still be picked up by hand) were constantly collected during the seedling and weeding stages. Therefore, fields with 30 years of intermittent mulching, as compared to fields with 6-8 years of continuous mulching, were subject to more plastic debris removal activities. On the contrary, the plastic films in continuous 
349 mulching fields were only collected once after the harvest of maize. The smaller particles were

350 remained in soils and experienced freeze-thaw cycles during the winter and spring, which also

351 posed more difficulties for manually removal. As a result, fields with 30 years intermittent

352 mulching accumulated fewer MaPs than continuous mulching fields. Another possible explanation

353 for this might be attributed to wind dispersion. Zylstra (2013) provided evidence that wind action

354 could spread substantial plastic debris between different ecosystems. Strong winds are very 355 common in the Gansu province (Guan et al., 2017). Hence, in the fields with over 30 years of 356 intermittent mulching, wind could have dispersed more agricultural plastic debris into other 357 environments and thus, lead to the significant lower accumulation of MaPs.

358 Crop rotation could have also affected the accumulation of MaPs. Looking closer at our 359 results of fields with 30 years intermittent mulching history in S1, S1-6 showed a higher number 360 of MaPs than S1-4 and S1-5. According to farmers, in S1-4, no plastic mulching was applied to 361 the field from 2015 to 2017 due to the crop rotation of oilseed rape (Early September 2015 to mid362 June 2016), winter Wheat (late September/early October 2016 to the end of May 2017), and 363 soybean (mid-June 2017 to late September 2017). In S1-5, the rotation of maize (mid-April 2017

364 to mid-September 2017, when plastic film was applied) and winter Wheat (late September/early

365 October 2017 to the end of May 2018) required farmland to be ploughed in September. However, 366 in S1-6, with a rotation of maize (mid-April 2016 to mid-September 2016, when plastic was 367 applied), left fallow ( mid-September 2016 to mid-June 2017) and Soybean (mid-June 2017 to 368 late September 2017), farmland was ploughed in May while still some plastic debris incorporated 369 into the soil. In addition, the winter could have accelerated the weathering and aging of MaPs. Any 370 of these things could have led to the higher MaPs number seen in S1-6 as compared to S1-4 and 371 S1-5. 
373

374

375 376

377 378

compared to other researches. In the same study region, Yan et al. (2008) discovered plastic residues of $259.9 \mathrm{~kg} \cdot \mathrm{ha}^{-1}$ (10 years) and $307.9 \mathrm{~kg} \cdot \mathrm{ha}^{-1}$ (20 years) in the soils of monocultural cotton. He et al. (2018) found that plastic residues (LDPE, LLDPE) ranged from 121.9 to 352.4 $\mathrm{kg} \cdot \mathrm{ha}^{-1}$ in fields where there were 5-19 years of mulching use. This discrepancy might be explained by the differences between the plastic debris sampling methods. In our field observations, the plastic films found on the surface of the soils were not taken into consideration for measurements since farmers claimed that these films would normally be removed along with the cotton stalk. In addition, in S2, the collected MaPs number and mass were not linearly increased with the mulching year, the highest accumulation was observed at 15 years mulching field. This emphasized that years of mulching use was not the main factor affecting the accumulation of agricultural plastic debris (Dong et al., 2015; Yan et al., 2014). As we mentioned in Material and method, fields in Xinjiang were subjected to high intensity machinery tillage, which lead to higher fragmentation of MaPs (Fig.3). The smaller particles were difficult to be collected and could also move into deeper soil layer, posed difficulties for MaPs recycle. In addition, combined with the strong winds in Xinjiang (Xiong et al., 2019), highly fragmented plastic debris in fields could be easily transferred to other environments by the wind (He et al., 2018; Rezaei et al., 2019; Steinmetz et al., 2016). The residual ratios measured in our two study regions suggested that the longer the plastic debris remained in the fields, the more likely that the plastic would disperse to other environments, which would affect the plastic debris accumulation and pose a threat to the environment. Overall, the accumulation pattern of MaPs in Xinjiang, a high machinery intensity region, subjected to many factors. Thus, the nonlinear increase of MaPs raises an important question: do other natural factors 
394 have significant effects on agricultural plastic accumulation? If so, what is the relative importance 395 of these different factors?

According to our results, in both two study regions, in general, MaPs number in 0-10 cm

397

398

399

400

401

402

403

404

405

406

407

408

409

410 411 et al., 2008).

412

413

414

415

416

soil showed no or less significant difference compared to 10-20 $\mathrm{cm}$, however, as for MaPs mass, 0-10 $\mathrm{cm}$ and 10-20 $\mathrm{cm}$ layers usually showed significant difference. This result indicated that even though 10-20 $\mathrm{cm}$ soil contained less amount MaPs compared to $0-10 \mathrm{~cm}$ soil, it still contained a significant MaPs number. Previous studies in China (Ma et al., 2008; Yan et al., 2008) have indicated that long-term tillage and intense machine tillage/ploughing might have homogenized the soil, especially in the top 0 to $20 \mathrm{~cm}$, thus leading to the insignificant differences seen for MaPs number among the various layers. This result also suggested that MaPs number $\left(\mathrm{p} \cdot \mathrm{ha}^{-1}\right)$ should also be an indicator for plastic pollution in future research. Machinery tillage intensity can also affect the size of the MaPs in soils. In our research, the majority size categories of the MaPs collected in $\mathrm{S} 1$ were $10-50 \mathrm{~cm}^{2}$ and $2-10 \mathrm{~cm}^{2}$, while for $\mathrm{S} 2$, the majority of collected MaPs were $0.25-2 \mathrm{~cm}^{2}$ and $2-10 \mathrm{~cm}^{2}$. These results indicate that the MaPs in S2 were more fragmented as compared to S1. These results agree with previous research findings that the sizes of plastic debris found in regions where applied with low-intensity machinery tillage are usually bigger than in regions where applied with high-intensity machinery tillage (Li et al., 2017; Ma et al., 2008; Yan

\section{Microplastics in agricultural soils}

In current research, MiPs were mainly detected in the soils exposed to 30 years of mulching history in S1 and were detected in all the selected fields in S2. These results are in agree with the MaPs number percentage results that in S2, MaPs were more fragmented than in S1. These results also indicated that long-term exposure of plastic debris in agricultural fields and high-intensity 
417 machine tillage could create more ubiquitous MiPs. Our MiPs results were far more less than

418 reported in other studies. Research conducted in southwestern China reported that MiPs were 419 detected in the range of 71 to $429 \mathrm{p} \cdot 10 \mathrm{~g}^{-1}$ in the $0-10 \mathrm{~cm}$ layer of soil in a vegetable production 420 system housed in a plastic greenhouse (Zhang and Liu, 2018). They attributed the higher MiPs to

421 the intense use of wastewater and sewage irrigation needed for the intensive vegetable rotation (6 422 to 8 crops per year). However, in our research, the cropping rotation and irrigation intensity were 423 less than those vegetable fields.

424 The rare MiPs detected in current research might be attributed to the extraction method 425 limitation mentioned in Material and method. However, the MiPs data in our research could be 426 regarded as a minimum estimation of accumulation of LDPE sourced MiPs in agricultural fields, 427 our work has made the attempt to connect MiPs pollution to plastic mulching use in a real in situ 428 study. More detailed research with better detection methods need to take place for a good 429 estimation of the amount of MiPs in the soil profile.

\section{Conclusions}

In this paper, we have shown that different farming systems can affected accumulation and 432 distribution of agricultural plastic debris (both MaPs and MiPs). Our study confirmed our 433 hypothesis that 1) under the same farming system (low-intensity machinery tillage), continuous 434 mulching could accumulate more MaPs than intermittent mulching; 2) high-intensity machinery 435 tillage farming system (S2) could lead to higher fragmentation of MaPs and lead to higher 436 fragmentation of MaPs and a create severer MiPs pollution as compared to low-intensity machine 437 tillage farming systems (S1). We also found that in S1, crop rotation system could affect ploughing 438 time (Spring or Autumn), thus affecting the accumulation of MaPs. The residual ratios were lower 439 for fields with a long mulching history. However, it remains unclear if this is due to wind and/or 
440 water transportation or due to further degradation of MaPs into smaller particles or even MiPs, 441 which are difficult to recycle. Further research on the degradation process of agricultural plastic 442 debris are needed, which could also provide a better understanding of the risk of agricultural MaPs 443 and MiPs and its effects on soil health and food quality.

\section{4}

445 


\section{Acknowledgements}

447 Many thanks to Yi Dang from Gansu Academy of Agricultural Sciences and Yu Liu from

448 Xinjiang Academy of Agricultural Sciences for helping to facilitate contact with local farmers and

449 for providing detailed information of local farming practices and plastic film specification. Thanks

450 to Demie Moore for checking and editing the language of this manuscript. Thanks to Nicolas Beriot

451 for providing the picture of setup of microplastic identification.

452 


\section{References}

454 Barnes, D.K., Galgani, F., Thompson, R.C., Barlaz, M., 2009. Accumulation and fragmentation of plastic debris in

455

456

457

458

459

460

461

462

463

464

465

466

467

468

469

470

471

472

473

474

475

476

477

478

479

480

481

482

483

484

485

486

487

488 global environments. Philos Trans R Soc Lond B Biol Sci 364, 1985-1998.

Blanco, I., Loisi, R.V., Sica, C., Schettini, E., Vox, G., 2018. Agricultural plastic waste mapping using GIS. A case study in Italy. Resources, Conservation and Recycling 137, 229-242.

Briassoulis, D., Aristopoulou, A., Bonora, M., Verlodt, I., 2004. Degradation Characterisation of Agricultural Lowdensity Polyethylene Films. Biosystems Engineering 88, 131-143.

Briassoulis, D., Babou, E., Hiskakis, M., Scarascia, G., Picuno, P., Guarde, D., Dejean, C., 2013. Review, mapping and analysis of the agricultural plastic waste generation and consolidation in Europe. Waste Manag Res 31, 1262-1278.

Cai, J., Zhang, F., Fan, X., Huang, M., Gao, L., 2013. The Status Quo of Film Application and Residue in the Southern Plains of China. Journal of Agricultural Resources and Environment 30, 23-30 (in Chinese with English abstract).

Cao, D., Wang, X., Luo, X., Liu, G., Zheng, H., 2017. Effects of polystyrene microplastics on the fitness of earthworms in an agricultural soil. IOP Conference Series: Earth and Environmental Science 61.

de Souza Machado, A.A., Kloas, W., Zarfl, C., Hempel, S., Rillig, M.C., 2018. Microplastics as an emerging threat to terrestrial ecosystems. Glob Chang Biol 24, 1405-1416.

Díaz-Hernández, J.L., Salmerón, T., 2012. Effects of a plastic cover on soil moisture change in a Mediterranean climatic regime. Soil Use and Management 28, 596-605.

Dong, H.D., Liu, T., Han, Z.Q., Sun, Q.M., Li, R., 2015. Determining time limits of continuous film mulching and examining residual effects on cotton yield and soil properties. J Environ Biol 36, 677-684.

Guan, Q., Cai, A., Wang, F., Yang, L., Xu, C., Liu, Z., 2017. Spatio-temporal variability of particulate matter in the key part of Gansu Province, Western China. Environ Pollut 230, 189-198.

He, H., Wang, Z., Guo, L., Zheng, X., Zhang, J., Li, W., Fan, B., 2018. Distribution characteristics of residual film over a cotton field under long-term film mulching and drip irrigation in an oasis agroecosystem. Soil and Tillage Research 180, 194-203.

Huang, Y., Liu, Q., Jia, W., Yan, C., Wang, J., 2020. Agricultural plastic mulching as a source of microplastics in the terrestrial environment. Environ Pollut 260, 114096.

Huerta Lwanga, E., Gertsen, H., Gooren, H., Peters, P., Salanki, T., van der Ploeg, M., Besseling, E., Koelmans, A.A., Geissen, V., 2016. Microplastics in the Terrestrial Ecosystem: Implications for Lumbricus terrestris (Oligochaeta, Lumbricidae). Environ Sci Technol 50, 2685-2691.

Ingman, M., Santelmann, M.V., Tilt, B., 2017. Agricultural water conservation in china: plastic mulch and traditional irrigation. Ecosystem Health and Sustainability 1, 1-11.

Jiang, X.J., Liu, W., Wang, E., Zhou, T., Xin, P., 2017. Residual plastic mulch fragments effects on soil physical properties and water flow behavior in the Minqin Oasis, northwestern China. Soil and Tillage Research $166,100-107$. 
489

490

491

492

493

494

495

496

497

498

499

500

501

502

503

504

505

506

507

508

509

510

511

512

513

514

515

516

517

518

519

520

521

522

523

524

525

Li, Y., Li, H., Wang, Y., Sun, Y., Wang, K., Yang, Q., 2017. Pollution Status and Control Countermeasures of Polyethylene Mulch Film Residue in Farmland Soils of Qingdao City, China. Journal of Agricultural Resources and Environment 34, 226-233 (in Chinese with English abstract).

Ma, D., Chen, L., Qu, H., Wang, Y., Misselbrook, T., Jiang, R., 2018. Impacts of plastic film mulching on crop yields, soil water, nitrate, and organic carbon in Northwestern China: A meta-analysis. Agric Water Manag 202, 166-173.

Ma, H., Mei, X., Yan, C., He, W., Li, K., 2008. The Residue of Mulching Plastic Film of Cotton Field in North China. Journal of Agro-Environment Science 27, 570-573 (in Chinese with English abstract).

Ma, S., Yang, Y., 2013. Investigation of Residual Plastic Film Pollution and Treatment Technologies in Xinjiang Farmland. Journal of Anhui Agri. Sci. 41, 13678-13681 (in Chinese with English abstract).

Ma, Y., Yang, H., 2015. Investigation on Pollution Caused by Mulching Plastic Film in Gansu Province and the Countermeasures. Journal of Ecology and R ural Environment 31, 478-483 (in Chinese with English abstract).

Mahon, A.M., O'Connell, B., Healy, M.G., O'Connor, I., Officer, R., Nash, R., Morrison, L., 2017. Microplastics in Sewage Sludge: Effects of Treatment. Environ Sci Technol 51, 810-818.

NBSC, 2017. China Rural Statistical Yearbook. China Statistics Press., Beijing.

Nuelle, M.T., Dekiff, J.H., Remy, D., Fries, E., 2014. A new analytical approach for monitoring microplastics in marine sediments. Environ Pollut 184, 161-169.

Qi, R., Jones, D.L., Li, Z., Liu, Q., Yan, C., 2020. Behavior of microplastics and plastic film residues in the soil environment: A critical review. Sci Total Environ 703, 134722.

Ramos, L., Berenstein, G., Hughes, E.A., Zalts, A., Montserrat, J.M., 2015. Polyethylene film incorporation into the horticultural soil of small periurban production units in Argentina. Sci Total Environ 523, 74-81.

Rezaei, M., Riksen, M., Sirjani, E., Sameni, A., Geissen, V., 2019. Wind erosion as a driver for transport of light density microplastics. Sci Total Environ 669, 273-281.

Rillig, M.C., 2012. Microplastic in terrestrial ecosystems and the soil? Environ Sci Technol 46, 6453-6454.

Scarascia-Mugnozza, G., Sica, C., Russo, G., 2011. Plastic Materials in European Agriculture: Actual Use and Perspectives. Journal of Agricultural Engineering 42, 15-28.

Scheurer, M., Bigalke, M., 2018. Microplastics in Swiss Floodplain Soils. Environ Sci Technol 52, 3591-3598.

Steinmetz, Z., Wollmann, C., Schaefer, M., Buchmann, C., David, J., Troger, J., Munoz, K., Fror, O., Schaumann, G.E., 2016. Plastic mulching in agriculture. Trading short-term agronomic benefits for long-term soil degradation? Sci Total Environ 550, 690-705.

Tarara, J.M., 2000. Microclimate modification with plastic mulch. Hortscience 35, 169-180.

Teuten, E.L., Saquing, J.M., Knappe, D.R., Barlaz, M.A., Jonsson, S., Bjorn, A., Rowland, S.J., Thompson, R.C., Galloway, T.S., Yamashita, R., Ochi, D., Watanuki, Y., Moore, C., Viet, P.H., Tana, T.S., Prudente, M., Boonyatumanond, R., Zakaria, M.P., Akkhavong, K., Ogata, Y., Hirai, H., Iwasa, S., Mizukawa, K., Hagino, Y., Imamura, A., Saha, M., Takada, H., 2009. Transport and release of chemicals from plastics to the environment and to wildlife. Philos Trans R Soc Lond B Biol Sci 364, 2027-2045.

Peer) reviewing PDF | (2020:07:50600:1:2:NEW 3 Oct 2020) 
526 Vermeiren, P., Munoz, C.C., Ikejima, K., 2016. Sources and sinks of plastic debris in estuaries: A conceptual model

527

528

529

530

531

532

533

534

535

536

537

538

539

540

541

542

543

\section{4} integrating biological, physical and chemical distribution mechanisms. Mar Pollut Bull 113, 7-16.

Xiong, Y., Zhang, Q., Chen, X., Bao, A., Zhang, J., Wang, Y., 2019. Large Scale Agricultural Plastic Mulch Detecting and Monitoring with Multi-Source Remote Sensing Data: A Case Study in Xinjiang, China. Remote Sensing 11.

Yan, C., He, W., Turner, N.C., Liu, E., Liu, Q., Liu, S., 2014. Plastic-film mulch in Chinese agriculture: Importance and problems. World Agriculture 4, 32-36.

Yan, C., Wang, X., He, W., Ma, H., Cao, S., Zhu, G., 2008. The Residue of plastic film in cotton fields in Shihezi, Xinjiang. Acta Ecologica Sinica 28, 3470-3474 (in Chinese with English abstract).

Zhang, D., Liu, H., Ma, Z., Tang, W., Wei, T., Yang, H., Li, J., Wang, H., 2017. Effect of Residual Plastic Film on Soil Nutrient Contents and Microbial Characteristics in the Farmland Scientia Agricultura Sinica 50, 310 319 (in Chinese with English abstract).

Zhang, G.S., Liu, Y.F., 2018. The distribution of microplastics in soil aggregate fractions in southwestern China. Sci Total Environ 642, 12-20.

Zhang, S., Yang, X., Gertsen, H., Peters, P., Salanki, T., Geissen, V., 2018. A simple method for the extraction and identification of light density microplastics from soil. Sci Total Environ 616-617, 1056-1065.

Zylstra, E.R., 2013. Accumulation of wind-dispersed trash in desert environments. Journal of Arid Environments 89, 13-15. 
Figure 1

Sampling site.

(A). Field measurements were conducted in two regions in Northwest China (Map data @ 2020 Google); (B). Study site Gansu (S1), was characterized by small plots and low intensity tillage; (C). Mulching pattern, duration, field area and crop rotation of the selected fields in S1; (D). Study site Xinjiang (S2), was characterized by large plots, lower plastic input and intensive machine tillage; (E). Mulching pattern, duration, field area and crop rotation of the selected fields in S2.

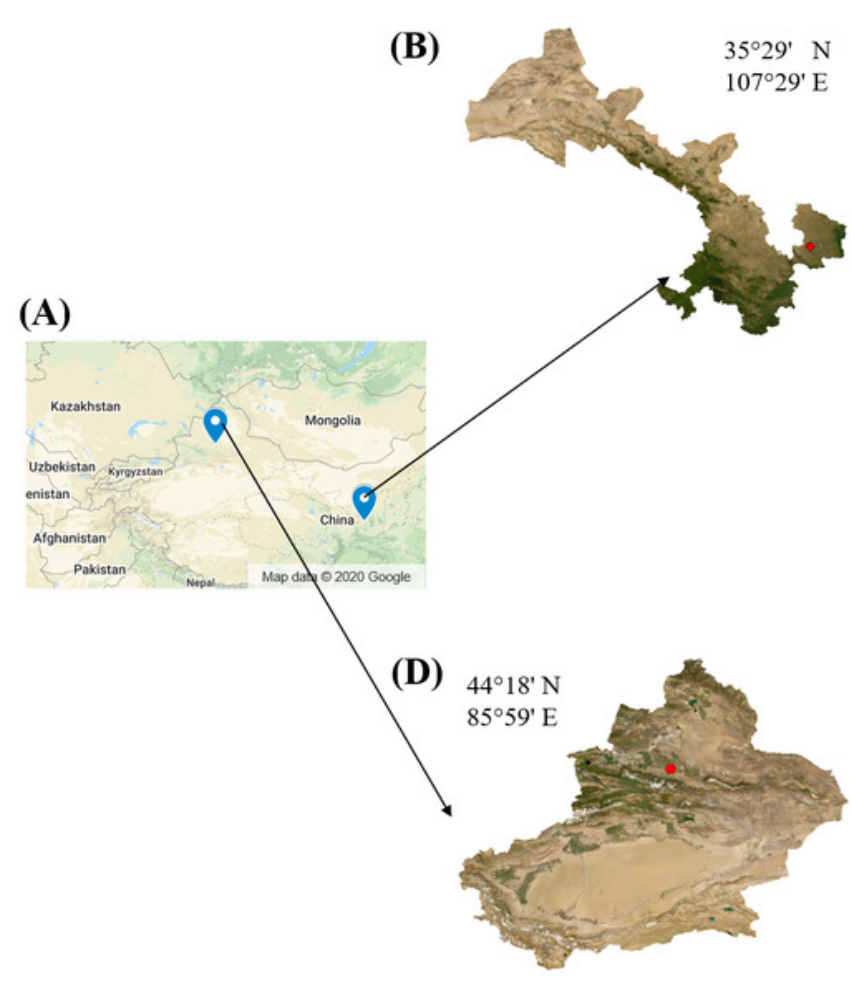

(C)

\begin{tabular}{|l|c|c|c|c|}
\hline Field & Mulching Pattern & Mulching Duration & Area (ha) & Crop (Rotation) \\
\hline Control_S1 & No mulching & - & 0.13 & Wheat \\
\hline S1-1 & Continuously FF & $2012-2017$ & 2.27 & Maize Monoculture \\
\hline S1-2 & Continuously FF & $2010-2017$ & 1.87 & Maize Monoculture \\
\hline S1-3 & Continuously FF & $2012-2017$ & 0.53 & Maize Monoculture \\
\hline S1-4 & Intermittently FF & Mid-1980s -2017 & 0.27 & Rape/Wheat/Soybean \\
\hline S1-5 & Intermittently FF & Mid-1980s - 2017 & 0.13 & Maize/Wheat \\
\hline S1-6 & Intermittently FF & Mid-1980s - 2017 & 0.27 & Maize/Soy Bean \\
\hline
\end{tabular}

(E)

\begin{tabular}{|l|c|c|c|c}
\hline Field & Mulching Pattern & Mulching Duration & Area (ha) & Crop (Rotation) \\
\hline Control_S2 & No mulching &.- & 2 & Fallow \\
\hline S2-1 & & $2012-2017$ & 5.3 & \\
\hline S2-2 & & $2011-2017$ & 4 & \\
\hline S2-3 & \multirow{2}{*}{ Continuously FCDI } & $2010-2017$ & 3.3 & Cotton \\
\cline { 3 - 4 } S2-4 & & $2003-2017$ & 7.2 & \\
\hline S2-5 & & $2000-2017$ & 7.2 & \\
\hline
\end{tabular}


Figure 2

Schematic of plastic mulching patterns

(A) Full film flat mulching (FF) in S1; (B) Flat cover with drip irrigation under plastic film (FCDI) in S2; (C). Sampling quadrats location in the field; (D). Sampling activity, the red dots represent the sampling points for extraction of Microplastics.
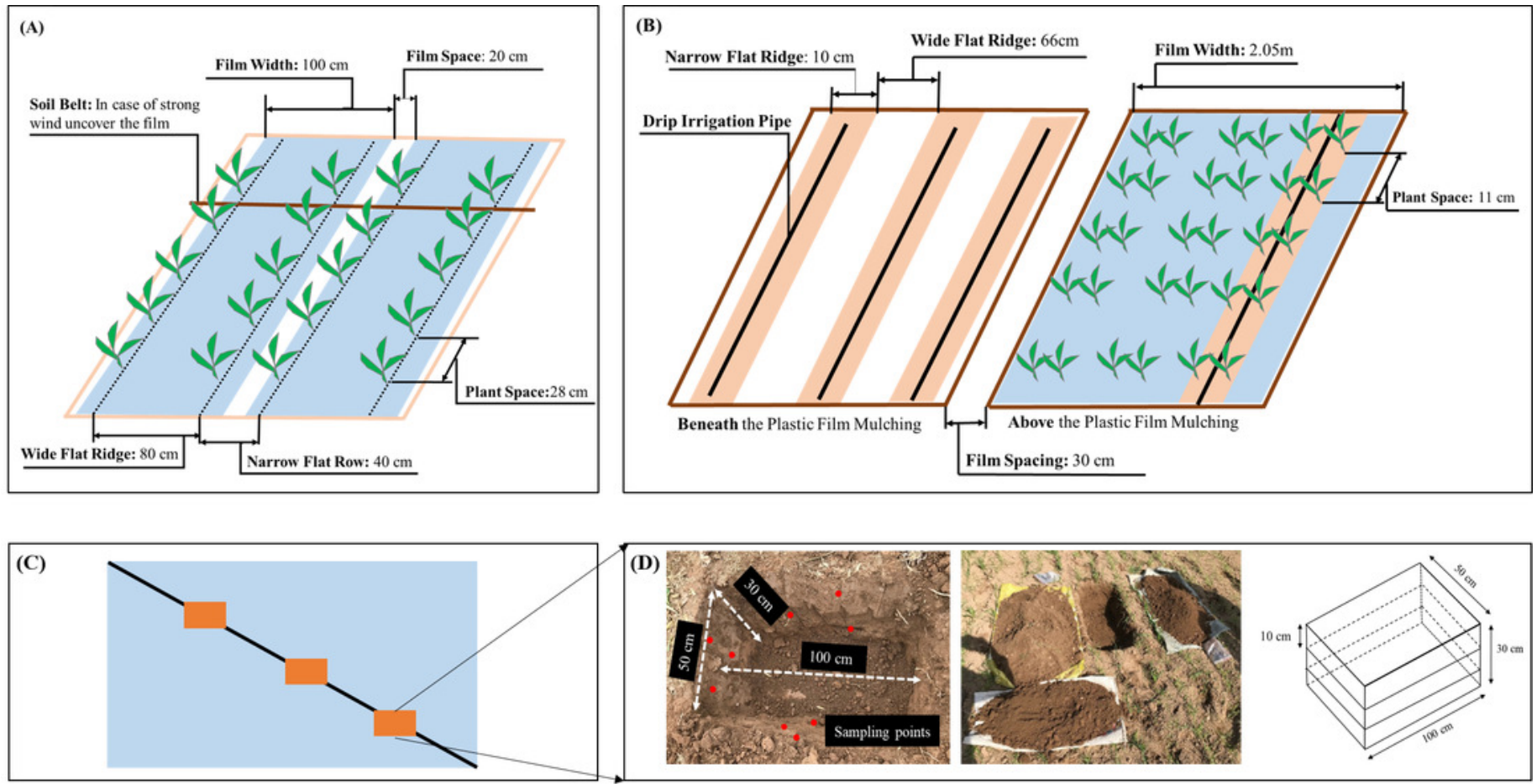


\section{Figure 3}

The percentages of number and mass of MaPs in different size categories

(A). The number percentages of MaPs in different size categories in 6-8 years continuous mulching fields (S1-1, S1-2 and S1-3) in S1; (B). The number percentages of MaPs in different size categories in over 30 years of intermittent mulching fields (S1-4, S1-5 and S1-6) in S1; (C). The number percentage of MaPs in different size categories in S2; (D). The mass percentage of MaPs in different size categories in continuous mulching fields (S1-1, S1-2 and S1-3) in S1; (E). The mass percentage of MaPs in different size categories in continuous mulching fields (S1-4, S1-5 and S1-6) in S1; (F). The mass percentage of MaPs in different size categories in S2. Lowercase letters (a,b,c,d) indicate significant differences between different size groups $(p<0.05)$.

(A)

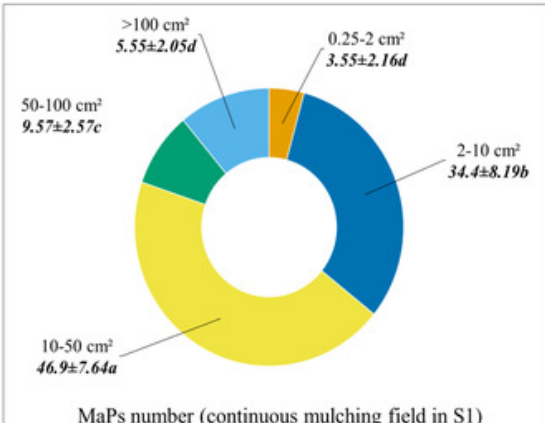

(D)

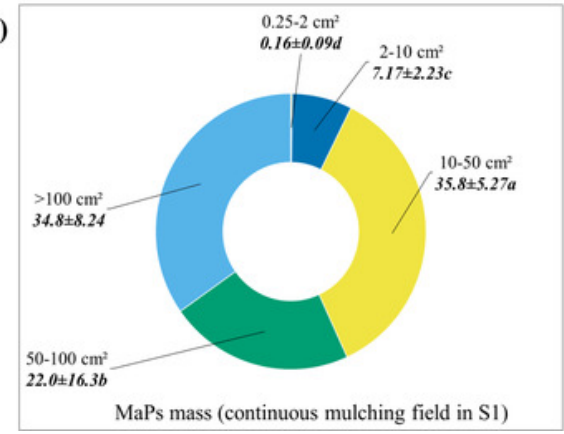

(B)

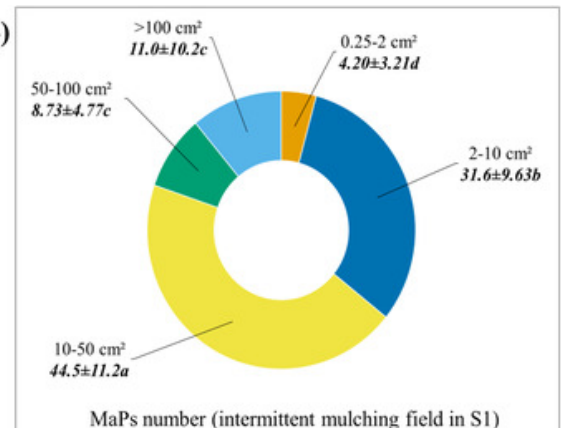

(E)

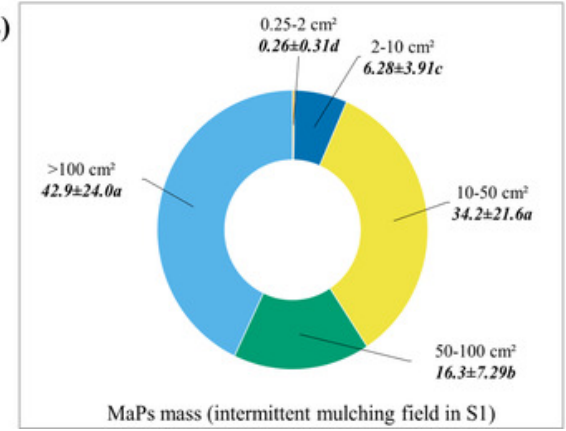

(C)

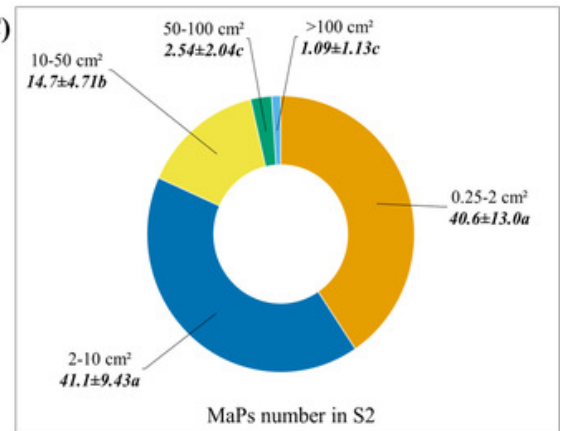

(F)

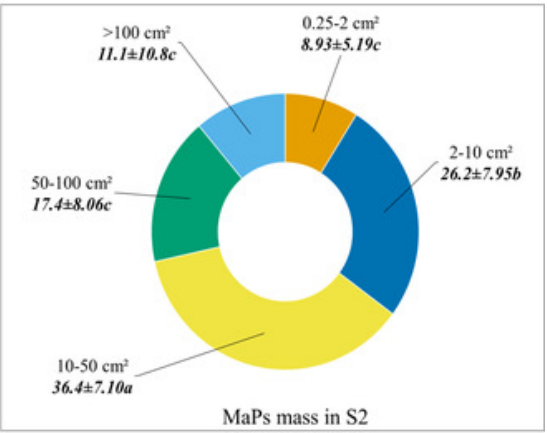




\section{Table $\mathbf{1}$ (on next page)}

Macroplastics number and content in $0-30 \mathrm{~cm}$ (one way ANOVA and followed by LSD test at the $p<0.05$ level)

Note: Lowercase letters $(a, b, c)$ indicate significant difference between different selected fields. In S1: S1-1: 6 years of FF mulching; S1-2: 8 years of FF mulching; S1-3: 6 years of FF mulching; S1-4, S1-5 and S1-6: 30 years history of intermittent FF mulching. In S2: S2-1: 6 years of FCDI mulching; S2-2: 7 years of FCDI mulching; S2-3: 8 years of FCDI mulching; S2-4: 15 years of FCDI mulching; S2-5: 18 years of FCDI mulching. 
Table 1: Macroplastics number and content in 0-30 cm (one way ANOVA and followed by LSD test at the $\mathrm{p}<0.05$ level)

\begin{tabular}{|c|c|c|c|}
\hline Study region & Sampling Site & $\begin{array}{l}\text { MaPs number } \\
\left(\times 10^{4} \mathrm{p} \cdot \mathrm{ha}^{-1}\right)\end{array}$ & $\begin{array}{c}\text { MaPs mass } \\
\left(\mathrm{kg} \cdot \mathrm{ha}^{-1}\right)\end{array}$ \\
\hline \multirow{6}{*}{ S1 } & S1-1 & $235 \pm 45.8 \mathrm{a}$ & $105 \pm 20.1 \mathrm{a}$ \\
\hline & S1-2 & $170 \pm 40.8 b$ & $97.4 \pm 22.0 \mathrm{a}$ \\
\hline & S1-3 & $265 \pm 12.9 \mathrm{a}$ & $108 \pm 13.2 \mathrm{a}$ \\
\hline & S1-4 & $88.0 \pm 22.3 \mathrm{c}$ & $56.1 \pm 37.3 b$ \\
\hline & S1-5 & $56.7 \pm 4.2 \mathrm{c}$ & $57.1 \pm 16.4 b$ \\
\hline & S1-6 & $155 \pm 58.2 b$ & $53.7 \pm 12.4 \mathrm{~b}$ \\
\hline \multirow{5}{*}{ S2 } & S2-1 & $502 \pm 201 \mathrm{c}$ & $43.5 \pm 9.3 \mathrm{c}$ \\
\hline & S2-2 & $650 \pm 136 c$ & $88.9 \pm 12.2 b$ \\
\hline & S2-3 & $461 \pm 79.1 \mathrm{c}$ & $80.6 \pm 18.6 b$ \\
\hline & S2-4 & $2,016 \pm 188 \mathrm{a}$ & $148 \pm 28.1 \mathrm{a}$ \\
\hline & S2-5 & $991 \pm 163 b$ & $81.1 \pm 3.93 b$ \\
\hline
\end{tabular}

Note: Lowercase letters $(a, b, c)$ indicate significant difference between different selected fields.

In S1: S1-1: 6 years of FF mulching; S1-2: 8 years of FF mulching; S1-3: 6 years of FF mulching; S1-4, S1-5 and S1-6: 30 years history of intermittent FF mulching.

In S2: S2-1: 6 years of FCDI mulching; S2-2: 7 years of FCDI mulching; S2-3: 8 years of FCDI mulching; S2-4: 15 years of FCDI mulching; S2-5: 18 years of FCDI mulching. 


\section{Table 2 (on next page)}

Residual ratios of MaPs in Wutong Village, Gansu Province (S1) \& Shihezi City, Xinjiang Province (S2)

Note. Total input was calculated using equation 3 and residual ratio was calculated using equation 4. Lowercase letters $(a, b, c, d)$ indicate significant differences between different selected fields within each selected study region $(p<0.05, n=3)$. Removal rate estimated based on farmers' information. 


\begin{tabular}{|c|c|c|c|c|c|c|c|}
\hline Study site & Sampling Site & Mulching Pattern & $\begin{array}{l}\text { Input per } \\
\text { application } \\
\left(\mathrm{kg} \cdot \mathrm{ha}^{-1}\right)\end{array}$ & Mulching Duration & $\begin{array}{l}\text { Total input } \\
\left(\mathrm{kg} \cdot \mathrm{ha}^{-1}\right)\end{array}$ & $\begin{array}{l}\text { Collected MaPs } \\
\left(\mathrm{kg} \cdot \mathrm{ha}^{-1} \text {, average }\right)\end{array}$ & $\begin{array}{c}\text { Residual ratio } \\
(\%)\end{array}$ \\
\hline \multirow{6}{*}{$\mathrm{S} 1$} & S1-1 & Continuously FF & \multirow{6}{*}{150} & $2012-2017$ & 900 & 105 & $11.7 \pm 2.23 \mathrm{a}$ \\
\hline & S1-2 & Continuously FF & & $2010-2017$ & 1200 & 97.4 & $8.12 \pm 1.83 \mathrm{a}$ \\
\hline & S1-3 & Continuously FF & & $2012-2017$ & 900 & 108 & $12.0 \pm 1.47 \mathrm{a}$ \\
\hline & S1-4 & Intermittently FF & & Mid-1980s - 2017 & 1050 & 56.1 & $5.34 \pm 3.56 \mathrm{~b}$ \\
\hline & S1-5 & Intermittently FF & & Mid-1980s - 2017 & 1050 & 57.1 & $5.44 \pm 1.56 \mathrm{~b}$ \\
\hline & S1-6 & Intermittently FF & & Mid-1980s - 2017 & 1050 & 53.7 & $5.11 \pm 1.19 b$ \\
\hline \multirow{5}{*}{ S2 } & S2-1 & \multirow{5}{*}{ Continuously FCDI } & \multirow{5}{*}{60} & $2012-2017$ & 360 & 43.5 & $12.1 \pm 6.76 \mathrm{ab}$ \\
\hline & S2-2 & & & $2011-2017$ & 420 & 88.9 & $21.2 \pm 7.64 \mathrm{a}$ \\
\hline & S2-3 & & & $2010-2017$ & 480 & 80.6 & $16.8 \pm 3.87 \mathrm{ab}$ \\
\hline & S2-4 & & & $2003-2017$ & 900 & 148 & $16.5 \pm 5.62 \mathrm{ab}$ \\
\hline & S2-5 & & & $2000-2017$ & 1080 & 81.1 & $7.51 \pm 0.36 \mathrm{~b}$ \\
\hline
\end{tabular}




\section{Table 3 (on next page)}

Macroplastics number and mass in different soil layer in S1 (one way ANOVA and followed by LSD test at the $p<0.05$ level)

Note: Lowercase letters $(a, b, c)$ indicate significant difference between different layers within same selected field. S1-1: 6 years of FF mulching; S1-2: 8 years of FF mulching; S1-3: 6 years of FF mulching; S1-4, S1-5 and S1-6: 30 years history of intermittent FF mulching. 
Table 3: Macroplastics number and mass in different soil layer in S1 (one way ANOVA and followed by LSD test at the $\mathrm{p}<0.05$ level)

\begin{tabular}{|c|c|c|c|}
\hline Sampling Site & Soil Layer & $\begin{array}{l}\text { MaPs number } \\
\times 10^{4}(\mathrm{p} / \mathrm{ha})\end{array}$ & $\begin{array}{c}\text { MaPs mass } \\
\mathrm{kg} \cdot \mathrm{ha}^{-1}\end{array}$ \\
\hline \multirow{3}{*}{ S1-1 } & $0-10 \mathrm{~cm}$ & $134 \pm 25.1 \mathrm{a}$ & $70.1 \pm 1.98 \mathrm{a}$ \\
\hline & $10-20 \mathrm{~cm}$ & $78.7 \pm 37.2 \mathrm{a}$ & $30.5 \pm 15.9 b$ \\
\hline & $20-30 \mathrm{~cm}$ & $22.7 \pm 15.5 b$ & $4.26 \pm 3.69 \mathrm{c}$ \\
\hline \multirow{3}{*}{$\mathrm{S} 1-2$} & $0-10 \mathrm{~cm}$ & $111 \pm 38.2 \mathrm{a}$ & $64.7 \pm 12.7 \mathrm{a}$ \\
\hline & $10-20 \mathrm{~cm}$ & $43.3 \pm 13.3 b$ & $28.2 \pm 16.5 b$ \\
\hline & $20-30 \mathrm{~cm}$ & $16.0 \pm 12.2 \mathrm{~b}$ & $4.50 \pm 3.19 \mathrm{c}$ \\
\hline \multirow{3}{*}{ S1-3 } & $0-10 \mathrm{~cm}$ & $173 \pm 27.3 \mathrm{a}$ & $82.3 \pm 10.6 \mathrm{a}$ \\
\hline & $10-20 \mathrm{~cm}$ & $69.3 \pm 21.9 b$ & $17.9 \pm 2.25 b$ \\
\hline & $20-30 \mathrm{~cm}$ & $22.0 \pm 11.1 \mathrm{c}$ & $8.13 \pm 7.93 b$ \\
\hline \multirow{3}{*}{ S1-4 } & $0-10 \mathrm{~cm}$ & $50.0 \pm 10.4 \mathrm{a}$ & $42.2 \pm 19.5 \mathrm{a}$ \\
\hline & $10-20 \mathrm{~cm}$ & $33.3 \pm 29.1 \mathrm{a}$ & $13.0 \pm 17.2 b$ \\
\hline & $20-30 \mathrm{~cm}$ & $4.67 \pm 3.06 \mathrm{~b}$ & $0.82 \pm 0.77 \mathrm{~b}$ \\
\hline \multirow{3}{*}{ S1-5 } & $0-10 \mathrm{~cm}$ & $30.0 \pm 7.2 \mathrm{a}$ & $33.6 \pm 18.4 \mathrm{a}$ \\
\hline & $10-20 \mathrm{~cm}$ & $19.3 \pm 2.31 \mathrm{a}$ & $14.7 \pm 1.11 \mathrm{ab}$ \\
\hline & $20-30 \mathrm{~cm}$ & $7.33 \pm 5.03 b$ & $6.79 \pm 6.97 \mathrm{~b}$ \\
\hline \multirow{3}{*}{ S1-6 } & $0-10 \mathrm{~cm}$ & $71.3 \pm 17.9 \mathrm{a}$ & $30.2 \pm 5.63 \mathrm{a}$ \\
\hline & $10-20 \mathrm{~cm}$ & $53.3 \pm 5.03 \mathrm{ab}$ & $16.1 \pm 1.42 b$ \\
\hline & $20-30 \mathrm{~cm}$ & $30.7 \pm 19.0 \mathrm{~b}$ & $7.30 \pm 5.84 \mathrm{c}$ \\
\hline
\end{tabular}

Note: Lowercase letters $(a, b, c)$ indicate significant difference between different layers within same selected field.

S1-1: 6 years of FF mulching; S1-2: 8 years of FF mulching; S1-3: 6 years of FF mulching; S1-4, S1-5 and S1-6: 30 years history of intermittent FF mulching. 


\section{Table 4 (on next page)}

Macroplastics number and content in different soil layer in S2 (one way ANOVA and followed by LSD test at the $p<0.05$ level)

Note: Lowercase letters $(a, b, c)$ indicate significant difference between different layers within same selected field. S2-1: 6 years of FCDI mulching; S2-2: 7 years of FCDI mulching; S2-3: 8 years of FCDI mulching; S2-4: 15 years of FCDI mulching; S2-5: 18 years of FCDI mulching. 
Table 4: Macroplastics number and content in different soil layer in S2 (one way ANOVA and followed by LSD test at the $\mathrm{p}<0.05$ level)

\begin{tabular}{|c|c|c|c|}
\hline Sampling Site & Soil Layer & $\begin{array}{l}\text { MaPs number } \\
\times 10^{4}(\mathrm{p} / \mathrm{ha})\end{array}$ & $\begin{array}{c}\text { MaPs mass } \\
\mathrm{kg} \cdot \mathrm{ha}^{-1}\end{array}$ \\
\hline \multirow{3}{*}{$\mathrm{S} 2-1$} & $0-10 \mathrm{~cm}$ & $241 \pm 24 a$ & $21.4 \pm 1.3 \mathrm{a}$ \\
\hline & $10-20 \mathrm{~cm}$ & $159 \pm 72.5 \mathrm{ab}$ & $11.6 \pm 4.53 b$ \\
\hline & $20-30 \mathrm{~cm}$ & $101 \pm 44.6 \mathrm{~b}$ & $10.4 \pm 5.05 \mathrm{~b}$ \\
\hline \multirow{3}{*}{ S2-2 } & $0-10 \mathrm{~cm}$ & $278 \pm 47 a$ & $51.7 \pm 4.6 \mathrm{a}$ \\
\hline & $10-20 \mathrm{~cm}$ & $216 \pm 55.2 \mathrm{ab}$ & $25.4 \pm 8.03 b$ \\
\hline & $20-30 \mathrm{~cm}$ & $156 \pm 40.8 b$ & $11.7 \pm 5.21 \mathrm{c}$ \\
\hline \multirow{3}{*}{$\mathrm{S} 2-3$} & $0-10 \mathrm{~cm}$ & $251 \pm 68.2 a$ & $52.0 \pm 9.07 \mathrm{a}$ \\
\hline & $10-20 \mathrm{~cm}$ & $162 \pm 118 \mathrm{ab}$ & $24.7 \pm 14.6 \mathrm{~b}$ \\
\hline & $20-30 \mathrm{~cm}$ & $48 \pm 29.5 b$ & $3.86 \pm 3.03 \mathrm{c}$ \\
\hline \multirow{3}{*}{ S2-4 } & $0-10 \mathrm{~cm}$ & $1,011 \pm 185 \mathrm{a}$ & $78.1 \pm 15.2 \mathrm{a}$ \\
\hline & $10-20 \mathrm{~cm}$ & $685 \pm 41 \mathrm{~b}$ & $50.9 \pm 8.13 b$ \\
\hline & $20-30 \mathrm{~cm}$ & $320 \pm 76 c$ & $19.1 \pm 11.2 \mathrm{c}$ \\
\hline \multirow{3}{*}{$\mathrm{S} 2-5$} & $0-10 \mathrm{~cm}$ & $467 \pm 34.5 \mathrm{a}$ & $49.6 \pm 5.00 \mathrm{a}$ \\
\hline & $10-20 \mathrm{~cm}$ & $336 \pm 130 \mathrm{ab}$ & $20.9 \pm 9.91 b$ \\
\hline & $20-30 \mathrm{~cm}$ & $188 \pm 87.1 \mathrm{~b}$ & $10.6 \pm 4.77 b$ \\
\hline
\end{tabular}

Note: Lowercase letters $(a, b, c)$ indicate significant difference between different layers within same selected field.

S2-1: 6 years of FCDI mulching; S2-2: 7 years of FCDI mulching; S2-3: 8 years of FCDI mulching; S2-4: 15 years of FCDI mulching; S2-5: 18 years of FCDI mulching. 


\section{Table 5 (on next page)}

Microplastics (MiPs) number $\mathrm{p} \cdot \mathrm{kg}^{-1}$ soil in S1.

Note. S1-1: 6 years FF mulching; S1-2: 8 years FF mulching; S1-3: 6 years FF mulching; S1-4, S1-5 and S1-6: 30 years history of intermittent FF mulching. 
Table 5. Microplastics (MiPs) number $\mathrm{p} \cdot \mathrm{kg}^{-1}$ soil in S1.

\begin{tabular}{ccccccccc}
\hline Soil layer & Replicates & Control & S1-1 & S1-2 & S1-3 & S1-4 & S1-5 & S1-6 \\
\hline \multirow{3}{*}{$0-10 \mathrm{~cm}$} & 1 & nd & nd & nd & nd & nd & 200 & 200 \\
& 2 & nd & 200 & nd & nd & nd & 100 & 800 \\
& 3 & nd & nd & nd & nd & 200 & nd & nd \\
\hline \multirow{3}{*}{$10-20 \mathrm{~cm}$} & 1 & nd & nd & nd & nd & nd & nd & 200 \\
& 2 & nd & nd & nd & nd & nd & nd & nd \\
& 3 & nd & nd & nd & nd & 100 & nd & nd \\
\hline \multirow{2}{*}{$20-30 \mathrm{~cm}$} & 1 & nd & 1 & nd & nd & 100 & 2200 & 1000 \\
& 2 & nd & nd & nd & nd & 100 & nd & nd \\
& 3 & nd & 100 & nd & nd & nd & 200 & nd \\
\hline
\end{tabular}

Note. S1-1: 6 years FF mulching; S1-2: 8 years FF mulching; S1-3: 6 years FF mulching; S1-4, S1-5 and S1-6: 30 years history of intermittent FF mulching. 


\section{Table 6(on next page)}

Microplastics (MiPs) number $\mathrm{p} \cdot \mathrm{kg}^{-1}$ soil in S2

Note. S2-1: 6 years FCDI mulching; S2-2: 7 years FCDI mulching; S2-3: 8 years FCDI mulching; S2-4: 15 years FCDI mulching; S2-5: 18 years FCDI mulching. $\mathrm{nd}=$ not detected 
Table 6. Microplastics (MiPs) number $\mathrm{p} \cdot \mathrm{kg}^{-1}$ soil in $\mathrm{S} 2$.

\begin{tabular}{cccccccc}
\hline Soil layer & Replicates & Control & S2-1 & S2-2 & S2-3 & S2-4 & S2-5 \\
\hline \multirow{3}{*}{$0-10 \mathrm{~cm}$} & 1 & nd & 600 & 300 & 300 & nd & 900 \\
& 2 & nd & nd & 400 & Nd & 100 & 700 \\
& 3 & nd & nd & nd & 900 & 800 & 400 \\
\hline \multirow{3}{*}{$10-20 \mathrm{~cm}$} & 1 & nd & nd & 100 & Nd & nd & 800 \\
& 2 & nd & nd & 800 & Nd & 400 & 100 \\
& 3 & nd & nd & nd & 100 & 400 & 100 \\
\hline \multirow{2}{*}{$20-30 \mathrm{~cm}$} & 1 & nd & 100 & nd & Nd & nd & 300 \\
& 2 & nd & nd & 600 & nd & nd & 300 \\
& 3 & nd & 100 & nd & 200 & 700 & 200 \\
\hline
\end{tabular}

Note. S2-1: 6 years FCDI mulching; S2-2: 7 years FCDI mulching; S2-3: 8 years FCDI mulching; S21

4: 15 years FCDI mulching; S2-5: 18 years FCDI mulching. $n d=$ not detected 